\title{
Research
}

\section{Establishing the Resilience of a Coastal-marine Social-ecological System to the Installation of Offshore Wind Farms}

\author{
Benjamin Burkhard ${ }^{1}$ and Kira Gee ${ }^{2}$
}

\begin{abstract}
Offshore wind farming is a contentious new form of sea use and a prominent driver of change across Europe. Drawing on the results of the research program Zukunft Küste - Coastal Futures, this contribution considers the resilience of the social-ecological system to the introduction of offshore wind farming in a northern German case study region. We do so by focusing on regime shifts and cross-scale effects, described through the concepts of adaptive cycles and ecosystem services. Offshore wind farming is shown to lead to a potential slow regime shift in the marine ecosystem, as well as a more rapid regime shift in the seascape. These shifts lead to changes in the available ecosystem services and conflicts between new and traditional sea and seascape values. We then explore the impact of these changes on the socioeconomic system on the coast. Against the background of the system's current state and constraints, we argue this impact could be creative and innovative, but this trajectory depends on an internal socio-political shift and willingness to change.
\end{abstract}

Key Words: cultural ecosystem services; German North Sea; offshore wind farming; regime shifts; social-ecological system dynamics

\section{INTRODUCTION AND AIMS}

Although a major part of the world's ecosystems has been converted to meet human needs (MA 2005), the increasing exploitation of marine areas for human activities is a rather new development (Kraberg et al. 2011). Offshore wind farming (OWF) is an example of a very recent development with the potential to cause significant impacts on the socialecological systems concerned (Gill 2005, Punt et al. 2009). Given the complexity of coastal and marine ecosystems and their current trend of becoming overused, it is important to understand potential consequences of OWF development and the processes that might cause social-ecological system shifts. A key question is how OWF-induced changes manifest themselves in the ecological and socioeconomic domains and whether changes in one domain can lead to changes in the others (Kinzig et al. 2006). OWF's diverse impacts on marine ecosystems have been documented already (Gill 2005, Petersen and Malm 2006, Wilhelmsson and Malm 2008, Inger et al. 2009). We trace the social-ecological system responses to OWF introduction at different spatial and temporal scales.

The case study is based on the integrated research project "Zukunft Küste - Coastal Futures" (www.coastal-futures.org; Lange et al. 2010) that looked at OWF as a new human activity entering a complex social-ecological system on the German North Sea coast (Fig. 1). Coastal Futures was a scenario-based prospective study that established a causal chain between OWF installation, changes in marine ecosystem functions, changes in the provision of marine ecosystem goods and services, and impacts on human well-being (Kannen and Burkhard 2009, Lange et al. 2010, Busch et al. 2011). An interesting aspect is that these effects occur at different spatial
Fig. 1. The case study area, comprising the administrative districts of North Frisia and Dithmarschen and the German Exclusive Economic Zone (EEZ; 12 nautical mile zone = German territorial sea). The map shows operating and possible future offshore wind farm developments in the southeastern North Sea (data sources: Zukunft Küste Coastal Futures project data, German Federal Maritime and Hydrographic Agency [BSH], and the German Energy Agency DENA).

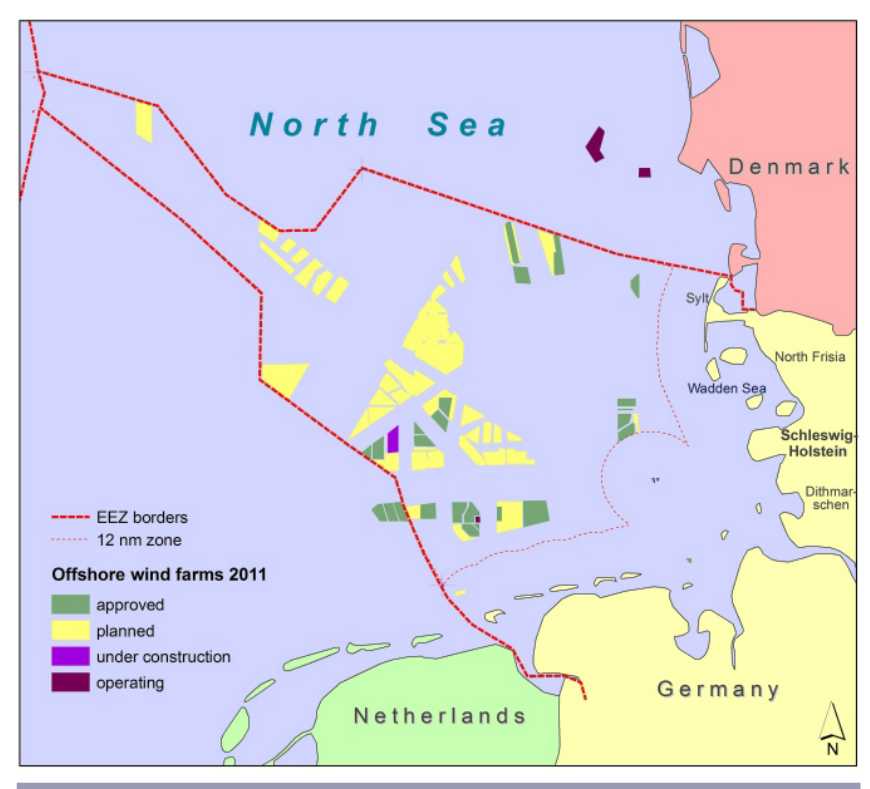


and temporal scales, implying that relatively small changes to the marine ecosystem, in the long or short term, could have consequences further down the line at the level of the seascape or local coastal communities, again in the long or short term. Although it is important to consider system changes within the individual domains of the system, the full implications of OWF introduction can therefore only be understood by considering effects across domains.

We seek to highlight potential regime shifts in the marine ecosystem and the possible transitions that may result from OWF development in the socioeconomic system on the coast (Loorbach and Rotmans 2006, Geels and Schot 2007). Extrapolating from OWF development scenarios and ecological and seascape-based results obtained in the Coastal Futures project, our purpose is to answer the following research questions:

- Do the Coastal Futures results provide evidence of potential regime shifts occurring as a result of OWF introduction?

- Partly as a result of regime shifts in the sea, will OWF introduction lead to a transition in the socioeconomic system on the coast? What factors would need to come into play for this transition to occur?

- What theoretical framework is able to capture and describe any cross-scale effects?

The third research question thus contains a methodological element, which is where our interest lies in linking concepts that have not yet been widely linked in the analysis of change in social-ecological systems. Linking the concepts of resilience, regime shifts, and the ecosystem services approach, we develop an innovative systems-theoretical framework that allows us to put the empirical results obtained in the Coastal Futures project into a broader heuristic context, opening up avenues for further comparative research.

We begin with a brief overview of the key concepts employed in our study. We then give some insight into the case study area and the methods used for analysis. This is followed by the presentation of two extreme system trajectories that could result from OWF introduction at three scales. We then discuss the results in the context of our theoretical framework.

\section{DEFINITIONS: RESILIENCE, REGIME SHIFTS AND ECOSYSTEM SERVICES}

The adaptive cycle (Bass 1998) is a useful background concept for describing OWF-related change in the ecological and socioeconomic systems considered here. It describes recurring dynamic behavior in the four characteristic phases of exploitation, conservation, release, and reorganization (Gunderson and Holling 2002), each of which exhibits different degrees of connectedness, capital accumulation, functions, flexibility, and resilience (Jørgensen et al. 2007).
An equivalent concept from the social sciences is that of transition, which describes a nonlinear shift in a societal system from one dynamic equilibrium to another. Here too, four phases of change can be recognized that occur at different speeds at the micro-, meso-, and macrolevel (Loorbach and Rotmans 2006).

Systems moving from the initial colonization phase to the conservation phase are characterized by growing connectedness, which essentially describes the density of links between the system components. Although this confers robustness, for instance by enabling communities to solve problems and build up social capital (Janssen et al. 2006), it can also make the system more inflexible, rendering it less and less able to absorb unexpected change. In both ecological and societal contexts, management efforts tend to be directed toward avoiding collapse (Folke et al. 2002a,b), although in the long term, perturbations and respective system reactions may be needed to increase system diversity and vigor (Walker and Salt 2006).

Resilience has been defined as a system's capacity to experience shocks while retaining essentially the same functions, structures, feedbacks, and therefore identity (Walker et al. 2006, 2007, Kirchhoff et al. 2010, Müller et al. 2010). A useful definition of social resilience is the resistive, stabilizing (in terms of structures), and regenerative response to threats or damage, bearing in mind that social resilience does not exist per se but always results from social processes and societal constructs of reality (Bürkner 2010). Throughout this paper we interpret resilience as resilience to change and the ability to maintain the status quo, which is one potential response of the ecological and/or socioeconomic system to OWF arrival (Fig. 2).

Fig. 2. Possible ecosystem responses to offshore wind farm (OWF) construction phases (adapted from Burkhard et al. 2011a). See text for further details.

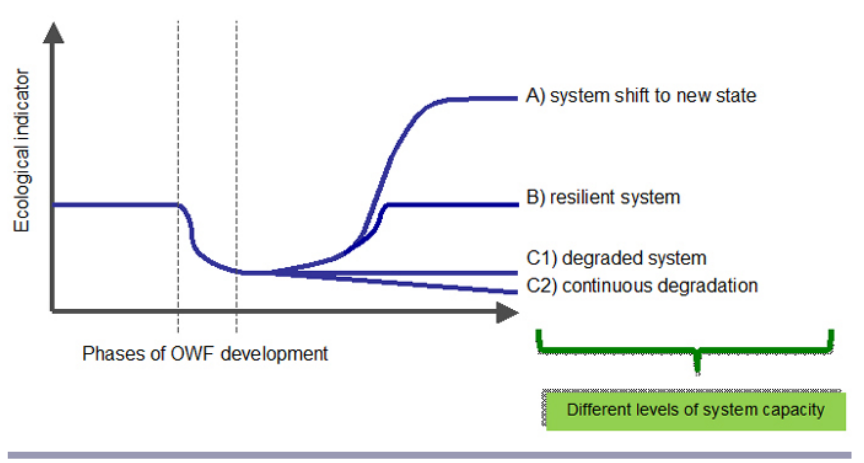

We borrow from network theory in arguing that connectedness, expressed as the capacity to maintain or (re) activate nodes and links in times of crisis, is an important constituent of resilience (Janssen et al. 2006). A resilient 
system, e.g., a particular marine ecosystem or local economy, would thus be able to absorb the perturbations arising from OWF introduction without experiencing instability and decline. Lost nodes and links such as species or actors and practices would be replaced by others, allowing the system to retain its overall identity. In a nonresilient system, this would not be the case; the disappearance or replacement of key system elements would trigger a cascade of changes that alter the identity of the system. Depending on the impact's nature and timing, nonresilient responses would be system degradation, defined here as the loss of particular functions, or the loss of key nodes and links of the system without their replacement by others (Janssen et al. 2006), or the eventual regime shift to a new state with increasing functionality and also a higher level of (bio)diversity, e.g., artificial reef ecosystems (Petersen and Malm 2006, Inger et al. 2009). In the socioeconomic system, a nonresilient response could be a negative transition, i.e., loss of structures and functions, or a positive transition, implying substitution of the existing regime by an equivalent or more diverse regime (Geels and Schot 2007).

Regime shifts describe significant system transformations based on temporary losses of resilience, leading to new functions, structures, feedbacks, and therefore identities (Kinzig et al. 2006). To make a regime shift take place, certain thresholds must be crossed and fundamental internal controls and feedbacks altered (Scheffer and Carpenter 2003). This also applies to the socioeconomic system, in which regime shifts can be triggered by internal and external disruptions of the system including specific shocks or niche innovation (Geels and Schot 2007). The question is whether OWF can trigger a positive system shift toward a new identity or is more likely to lead to gradual decline. A key factor determining the socioeconomic system trajectory is the alignment of the microlevel, that is, individual actors and local practices, e.g. niche innovations; the meso-level, e.g., institutional strategies, policy contexts, interests, rules, and belief systems; and the macrolevel, e.g., wider societal norms and values (Loorbach and Rotmans 2006).

Ecosystem services are the ecological, socio-cultural, and economic ecosystem benefits and values that contribute directly or indirectly to human well-being (Kumar 2010). Ecosystem services provide a logical link between the ecological and socioeconomic system (Bossel 2000), so that changes in ecosystem service supply can be used to trace regime shifts and possible cascading effects of such shifts across scales. In our case study, OWF-based regime shifts in local marine ecosystems would impact on the functioning of these ecosystems either limited to the scale of individual wind turbine piles and foundations or whole wind farms (Petersen and Malm 2006). This may impact on provisioning ecosystem services such as food from fishery or mariculture, marine biochemicals, and wind energy supply (Punt et al. 2009). At the seascape scale, shifts in cultural ecosystem service supply come into play, leading to changes in aesthetic seascape values, spiritual services, sense of place, identity, and inspiration (MA 2005, Gee and Burkhard 2010). Changes in the provision of these services are likely to impact on a multitude of benefits available to humans on the coast, potentially shifting the socioeconomic structures of the system and leading to changes in the capacity of that system to contribute to human welfare (Gill et al. 2005, Busch et al. 2011).

For the purpose of our case study we consider resilient or adaptive responses to occur at three distinct OWF scales (Fig. $3)$. Each of these corresponds to a specific spatial level and can also be understood as a distinct domain or subsystem of the social-ecological system. First is the scale of individual wind turbine piles, which represents the introduction of hard substrate on the sea floor (at the same time, the smallest unit on a spatial scale or the micro- and meso-scale according to Petersen and Malm 2006). Second is the scale of one or several offshore wind farms, where OWF introduction represents a collection of new man-made structures in the sea and an impact on the seascape (the intermediate level on the spatial scale or macroscale after Petersen and Malm 2006). Third is OWF as a novel way of utilizing marine space and a new economic regime based on renewable energies (the regional, national, and even international level on the spatial scale). Effects will manifest themselves at different speeds and across scales.

Fig. 3. Conceptual model illustrating the linkages between the offshore wind farm (OWF) case study and the potential future system trajectories.

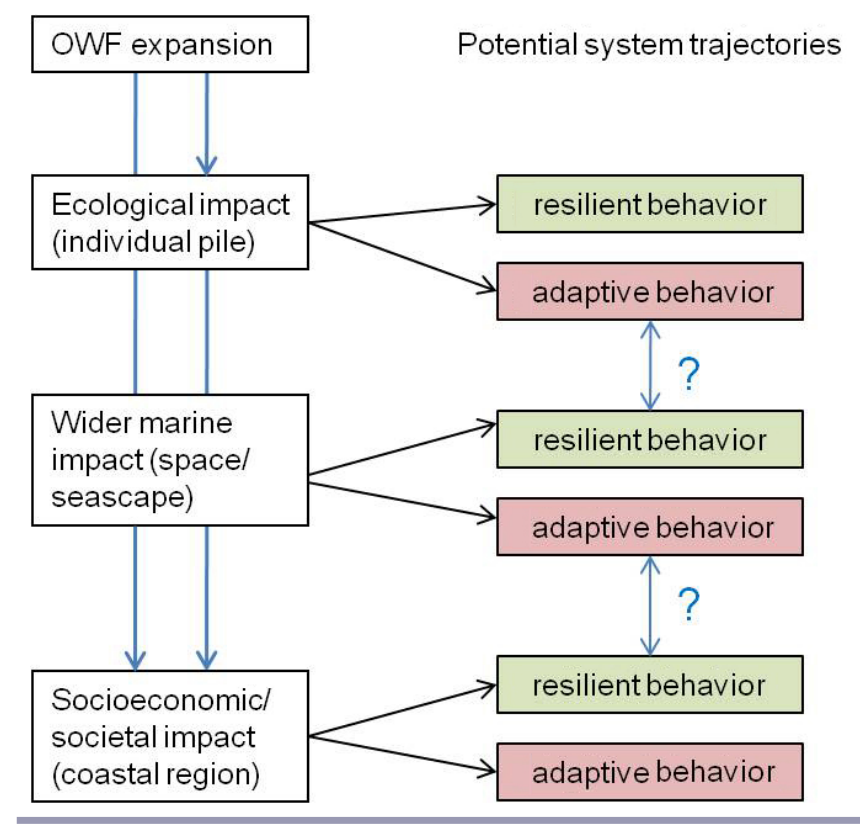


OWF introduction will act directly on all three subsystems, with changes in the seascape conceivably and indirectly acting on the socioeconomic system on the coast. The question is thus whether OWF introduction forces regime shifts at the respective levels and whether these are interrelated in any way.

\section{CASE STUDY AREA}

Current plans of the German government schedule a total of about 5000 wind turbines in the German share of the North Sea by 2030 with a capacity to deliver a total of 25,000 MW in electricity (Kannen and Burkhard 2009). If these plans are realized, OWF would cover a large part of Germany's Exclusive Economic Zone (EEZ). Because the majority of these OWFs have not yet been built (see Fig. 1), the Coastal Futures project worked with future scenarios assuming different OWF developments in the case study area (Lange et al. 2010). Different ecological models were used to assess the environmental impacts of the assumed scenarios (Burkhard et al. 2011a). In a parallel investigation, interviews and expert assessments were used to evaluate the potential effects of OWF expansion on seascape values and related ecosystem services, as well as the secondary effects on human well-being in the case study area (Busch et al. 2010, 2011, Gee and Burkhard 2010).

\section{Key socioeconomic characteristics of the case study area} To understand the potential social-ecological system response to OWF introduction, some key characteristics of the case study region need to be described. The districts of Dithmarschen and North Frisia are some of the remotest and structurally weakest regions of the German federal state of Schleswig-Holstein (BBR 2005). Although (subsidized) agriculture also plays an important role, the region relies on tourism as its economic mainstay in terms of employment and income generated (Ziesemer and Zahl 2005). Onshore wind energy has grown considerably over recent years and is estimated to have created 1400 jobs in North Frisia (Ziesemer and Zahl 2005). The density of onshore wind farms in both districts is correspondingly high, with more than 600 wind turbines in North Frisia and about 800 in Dithmarschen (Kreis Dithmarschen 2009).

Despite the positive economic impact of the onshore wind industry, the socioeconomic system in the region is characterized by structural vulnerability. In the early 1990s the region was hit by comprehensive structural change and experienced a subsequent period of decline. The tourism sector responded with investments in infrastructure and more targeted marketing, which led to a reasonably stable conservation phase but also increased the region's dependence on a particular type of tourism. The special quality of the Wadden Sea coast and seascape is a key factor in marketing (Hasse 2007), which makes some local people and tourism operators highly suspicious of any potential threats to the seascape such as OWF (e.g., Gegenwind Sylt 2011, www. gegenwind-sylt.de).

Other vulnerability factors include the importance of external subsidies for agriculture and the wind industry, as well as negative demographic trends and a large retirement community (Licht-Eggert et al. 2007). Unemployment rates are comparatively high and the average household income is relatively low compared to the rest of Germany (Statistisches Amt für Hamburg und Schleswig-Holstein 2007). Both districts have been ranked in positions of low to average strength in an assessment of different German regions' fitness for the future based on 26 socioeconomic indicators and measured by, e.g., expected economic growth or changes in job density (Prognos AG 2005). The situation is not helped by the fact that the region is comparatively far from the regional center of government and is embedded in a hierarchical institutional framework and relatively inflexible, formal modes of governance (Bruns and Gee 2009). Given this susceptibility to sudden or gradual changes in external driving forces and limited ability to compensate for structural losses from within, e.g., through innovation, OWF could offer an opportunity for putting the region on a more secure economic footing, for instance by investing in the growing OWF servicing industry.

At the same time, there is an apparent paradox in that the structural weakness described above is actually counted as an advantage with respect to social system orientors at the individual level. Residents perceive life in a remote rural region and the beauty of the land- and seascape as strong contributors to quality of life and are suspicious of any change (Bruns and Gee 2010, Ratter and Gee 2012). A strong sense of identity and attachment to home, the land- and seascape, and traditions are also characteristic, as is a good measure of local pride (Ratter and Gee 2012). This goes hand in hand with the independence of the local population and their desire to be as self-sufficient in decision making as possible (Bruns and Gee 2010). Offshore wind farming therefore not only represents a threat to the visual aesthetics upon which tourism depends, but also to local control.

\section{MEASURING THE IMPACT OF OWF INTRODUCTION ON THE CASE STUDY SYSTEM}

Impact of OWF introduction on the marine ecosystem OWF introduces hard structures into the sea, leading to direct impacts on marine ecosystems. Petersen and Malm (2006) conclude that in marine areas with little or no hard substrates, OWF have the potential to completely alter the characteristics of local species composition. This may lead to the creation of new habitats, i.e., artificial reefs, up to the OWF scale. Thus, at least local impacts at the scale of individual turbine piles are to be expected. Punt et al. (2009) demonstrated possible spatial spill-over effects of artificial reefs and no-take zones 
Table 1. Indicators used for the description of potential offshore wind farming (OWF)-related ecosystem development and impacts on cultural ecosystem services (adapted from Busch et al. 2010).

\begin{tabular}{|c|c|}
\hline & Potential OWF impacts \\
\hline \multicolumn{2}{|l|}{ Ecosystem functions } \\
\hline Exergy capture & The insertion of hard structures and substrates into the sea might cause changes in primary production. \\
\hline Entropy production & $\begin{array}{l}\text { OWF can cause changes in internal energy use (the gross primary production/net primary production ratio would change); thus, } \\
\text { entropy production would change. }\end{array}$ \\
\hline Nutrient cycling & $\begin{array}{l}\text { Ecosystem alterations around the turbine piles and scour protection will alter nutrient turnover rates around the piles. Additional } \\
\text { effects are expected because of wake effects and the settlement of benthic organisms. }\end{array}$ \\
\hline Storage capacity & $\begin{array}{l}\text { Ecosystem alterations around the turbine piles and scour protection will change the amount of matter, e.g., organic carbon, stored } \\
\text { in the system. }\end{array}$ \\
\hline Abiotic heterogeneity & $\begin{array}{l}\text { The insertion of hard structures and substrates in the form of wind turbine piles and scour protection provides new and more } \\
\text { heterogeneous habitats for the settlement of, e.g., benthic organisms. Additionally, water currents and sediment dynamics are } \\
\text { locally influenced. }\end{array}$ \\
\hline Biotic diversity & $\begin{array}{l}\text { Ecosystem alterations around the turbine piles and scour protection will change underwater species diversity. Further impacts on } \\
\text { above-water species diversity (migrating and resting birds) and impacts on marine mammals are expected. As commercial } \\
\text { fishery is not allowed within OWFs because of shipping safety reasons, species diversity will change. }\end{array}$ \\
\hline Nutrient loss & $\begin{array}{l}\text { Ecosystem alterations around the turbine piles and scour protection will change nutrient cycling, altering nutrient losses in the } \\
\text { surroundings of the OWFs. }\end{array}$ \\
\hline Organization & $\begin{array}{l}\text { Ecosystem alterations around the turbine piles and scour protection will change ecosystem organization with regard to matter, } \\
\text { information, and energy fluxes. }\end{array}$ \\
\hline \multicolumn{2}{|c|}{ Cultural ecosystem service indicators } \\
\hline Visual aesthetics & If visible, OWFs would add a new element to the seascape, affecting the visual qualities of the sea (wide open horizon) \\
\hline Seascape character & OWF shifts the character of the seascape from a largely natural to a more industrial landscape. \\
\hline Sense of place & $\begin{array}{l}\text { OWF is incompatible with the desire to keep the sea free of industrial structures and challenges the traditional view of the } \\
\text { seascape/area. Aspects of control and decision making processes could be important. Indirect impacts, e.g., helicopter flights, } \\
\text { could detract from what are now considered essential elements of "Heimat," e.g., peace and quiet, remoteness. }\end{array}$ \\
\hline Cultural heritage & $\begin{array}{l}\text { In the long term, OWFs could become an accepted element of the cultural landscape. Short-term impacts could include the } \\
\text { destruction of archaeologically important sites (bad siting of OWFs). }\end{array}$ \\
\hline $\begin{array}{l}\text { Habitat and species } \\
\text { value }\end{array}$ & $\begin{array}{l}\text { OWF could fundamentally change natural habitats and impact on bird and mammal species. OWF is perceived as a potential } \\
\text { threat to intrinsic natural values. }\end{array}$ \\
\hline Regional image & $\begin{array}{l}\text { OWF can make a positive contribution to the region's image in helping it to modernize. OWF can also be negative if it is seen to } \\
\text { detract from essential traditional qualities. The nature of the impact depends on the choices the region makes for its future. }\end{array}$ \\
\hline Inspiration & $\begin{array}{l}\text { In adding a new element to the environment, OWF can act as a source of inspiration or detract from previous sources of } \\
\text { inspiration. The effect is likely to be stronger the more visible OWFs would be. }\end{array}$ \\
\hline Informal education & OWF represents a new topic that can be added to existing informal education issues. \\
\hline Knowledge systems & $\begin{array}{l}\text { In the mid- to long-term, OWF could bring new local and scientific knowledge to the region, i.e., technology transfer, } \\
\text { accumulation of more and different types of knowledge. }\end{array}$ \\
\hline Recreation & $\begin{array}{l}\text { Impacts could include new recreational activities such as trips to wind farms. OWF may impact on personal feelings of well- } \\
\text { being. If visible, leisure may be affected, e.g., enjoying the open horizon. }\end{array}$ \\
\hline
\end{tabular}

for fish using a numerical model example for the Dutch part of the North Sea. Gill (2005) expects even larger scale cumulative impacts for the whole North Sea because of several larger OWF projects adjacent to each other. Several studies (Peterson and Malm 2006, Vattenfall 2009, Nilsson and Green 2011) assume minor or no negative effects on the marine environment whereas others expect major problems for birds (Exo et al. 2003) and marine mammals (Skeate et al. 2012). Several authors list positive environmental effects related to OWF installations, such as increase in local biodiversity, artificial reef emergence, no-take fishery zones, as well as negative effects, which are mainly avian collisions, underwater noise, and electromagnetic fields (Gill 2005, Inger et al. 2009, Punt et al. 2009). Regarding temporal scales, shortterm impacts are likely to take place during OWF construction and long-term impacts during OWF operation. Coastal Futures used various ecological models to assess the likely impact of OWF installation on the marine ecosystem in the case study area (Table 1; for details see Lenhart et al. 2010, Burkhard et al. 2011a).

In other countries, the introduction of large-scale OWF has been shown to have impacts on the seascape (Hill et al. 2001, DTI 2005). Offshore turbines represent a visible industrialization of the sea, supporting its conversion from a natural space to a cultural seascape (Wolsink 2010). In the UK for example the aesthetic impact of nearshore wind farms has given rise to widespread local concern (see Save Our Scenery, www.saveourscenery.com/environmental assessment.htm), although in Belgium, $78 \%$ of the public were neutral to very positive in their attitude to an offshore wind farm that would be built at a distance of $\sim 6 \mathrm{~km}$ from the coast (Wizelius 2007). Given the wide range of uses of other fixed installations such as oil platforms, the existing seascape must be considered a multifunctional seminatural landscape. OWF introduces new seascape attributes, with potentially considerable effects on 
existing cultural ecosystem services. Coastal Futures used a customized set of cultural ecosystem services indicators to trace the value shifts that would arise through OWF in the seascape (Table 1).

Socioeconomic resilience is a highly complex entity that includes orientors at the individual level, e.g., personal health, social security, employment, education, culture, as well as system-oriented factors, e.g., effectiveness, freedom of action, security, adaptability, coexistence (see Bossel 2000 on basic orientors of a system's survival). At the individual level, we use survey results to evaluate the importance of cultural ecosystem services and their significance for subjective quality of life (Busch et al. 2011). Structurally, we work with the premise of existing structural vulnerability (Licht-Eggert et al. 2007), which we understand to reduce the system's buffer capacity against changes in external driving forces. These could be an economic crisis forcing tourists to stay away, cuts in subsidies to the agricultural or wind farming sector, or changes in national energy policy. However, even without externally driven change, a "business as usual" scenario would leave the region vulnerable to slow and gradual change such as demographic change. This would have impacts on infrastructure, employment, and satisfaction and most likely lead to a self-reinforcing cycle of gradual decline.

\section{RESULTS}

\section{Resilience of the marine ecosystem}

Results of ecological modeling (for details see Lenhart et al. 2010, Burkhard et al. 2011a) show that some of the selected indicators are sensitive to disturbances during OWF construction (Fig. 4). Most parameters indicate resilient ecosystem behavior, meaning that processes and structures return to a state comparable to the reference conditions. One exception is seabird species diversity (indicating biotic diversity), whereby permanent habitat loss is likely to result from OWF for selected species (Exo et al. 2003, Lenhart et al. 2010). Further exceptions are storage capacity, abiotic heterogeneity, organization, and nutrient cycling, which all increase very slightly. This could be taken as a first indication for the emergence of a more complex ecosystem, resulting from the introduction of hard structures. Such artificial reef effects, providing additional habitats, accumulating biomass, and enhancing the area's productivity, have been described by several authors (e.g., Gill 2005, Petersen and Malm 2006, Inger et al. 2009, Punt et al. 2009) and were observed at existing OWFs shortly after construction (Vattenfall 2006, 2009). At the existing OWFs, ecosystem dynamics based on rapidly settling species, e.g., blue mussels, barnacles, crabs, took place at wind turbine piles. True artificial reef emergence, e.g., with higher animal species abundance, was not yet found at OWFs, but as long-term studies on artificial reefs have shown, it takes about five years before stable communities are established (Petersen and Malm 2006).
Fig. 4. Synoptic overview of ecosystem development related to different phases of offshore wind farm (OWF) installations in the German North Sea. The reference state (the German North Sea without OWF) is indicated by $100 \%$, alterations during construction and operation of wind farms are indicated by relative deviations (in \%) from these reference values (based on Burkhard et al. 2011a).

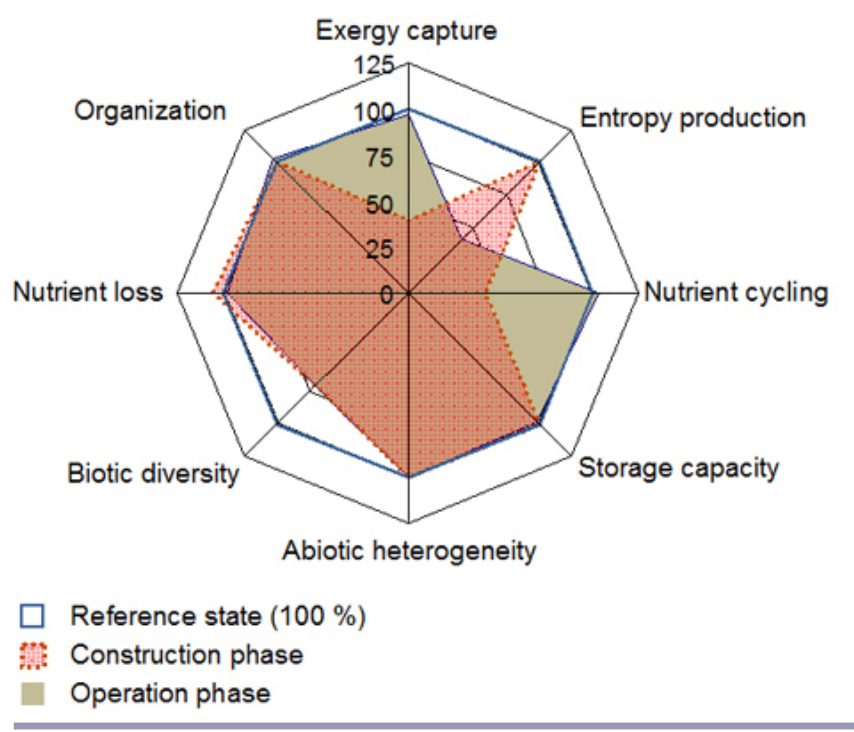

The development of artificial reefs would indicate a regime shift that clearly contrasts with the alternative, a degradation of the existing system. Once fully realized, the new system state would be characterized by a higher level of ecosystem functionality.

The question remains up to which of the three studied spatial scales these effects would occur. Petersen and Malm (2006) predict respective habitat alterations up to their macroscale, which corresponds to our OWF scale. Gill (2005) assumes that each individual OWF will have a footprint of $20-50 \mathrm{~km}^{2}$ or greater that would lead to massively cumulating effects of all larger OWF projects on the marine ecosystems. Comparison to existing OWF projects and their environmental impacts is feasible up to a certain degree only because of the sheer scale of the proposed developments in Germany (Fig. 1). Apart from the high number of turbines to be installed (Kannen and Burkhard 2009), there are also plans for significantly larger turbine size (at least 5 MW each) with more complex foundation constructions, greater distances to the coast $(\sim 30$ $\mathrm{km}$ minimum), and water depths of $\sim 25 \mathrm{~m}$.

If larger scale effects occur, the development of artificial reefs could have visible and measurable secondary effects on the linked socioeconomic system. For example, several North Sea fish species are known to utilize rocky substrates at some life stages. It is thus imaginable that a provable effect on the 
recruitment of some commercially important species could develop (Wilhelmsson et al. 2006). This could lead to an increasing food provisioning ecosystem service fish, benefiting the fishery sector's welfare (Lenhart et al. 2010). Thus, trade-offs between different ecosystem services and values, for instance, losses of migratory birds, marine mammals, (Lange et al. 2010) as well as seascape values, have to be assessed.

\section{Resilience of the seascape}

OWF alters the seascape in that it introduces large-scale fixed structures into a space where previous uses have been mostly fleeting. As such, OWF represents a shift toward greater industrialization of the sea. The survey of local residents in the case study area indicates that this industrialization effect is felt irrespective of the visibility of OWF (Gee 2010a). This is due to the prevalent view of the sea as a largely nonindustrial space where human impact has so far remained restricted; there is also the view that the sea should be kept free of man-made structures and that interests such as nature conservation should have priority.

In terms of regime shifts, this indicates the existence of two distinct seascape states that in their extreme expressions are mutually exclusive. If the sea is considered a natural space, not to be built up, then any expansion of OWF would constitute a regime shift; the introduction of built-up structures would prevent the seascape from returning to its previous natural state and thus change its identity. The seascape would show an adaptive response in that it becomes a more manifestly cultural landscape. This shift would be all the more pronounced the more the planned OWFs are realized. Even though the removal of turbines could in theory put the seascape back to its original state, this is an unlikely prospect at least in the medium term because OWF is a difficult and costly prospect to reverse.

Cultural ecosystem services describe the regime shift taking place in the seascape in more detail. Figure 5 is based on the responses obtained in the residents' survey and reflects their overall rating of the cultural ecosystem service shift, comparing potential OWF impacts on regional cultural ecosystem services (blue lines) with the existing values attributed to the sea (yellow reference line; Busch et al. 2010). Because of the highly subjective nature of the perceived impacts of OWF, many of the services in Figure 5 show a range of potential responses, depending on whether the individual observer considers the shift as something that adds value or causes loss of value. The aesthetic category is unusual in the German context because most of the planned OWFs are not positioned nearshore, rendering the visibility argument a tenuous one. However, the current maritime spatial planning framework does allow OWFs to be built throughout the EEZ, so that visibility could become an issue for the islands of North Frisia. More importantly perhaps, the aesthetics argument is instrumentalized by many local residents as a general, and not altogether rational, argument against change.

Fig. 5. Impacts of offshore wind farming on cultural ecosystem services in the case study area (from Busch et al. 2010)

Local / islands and municipalities scale:

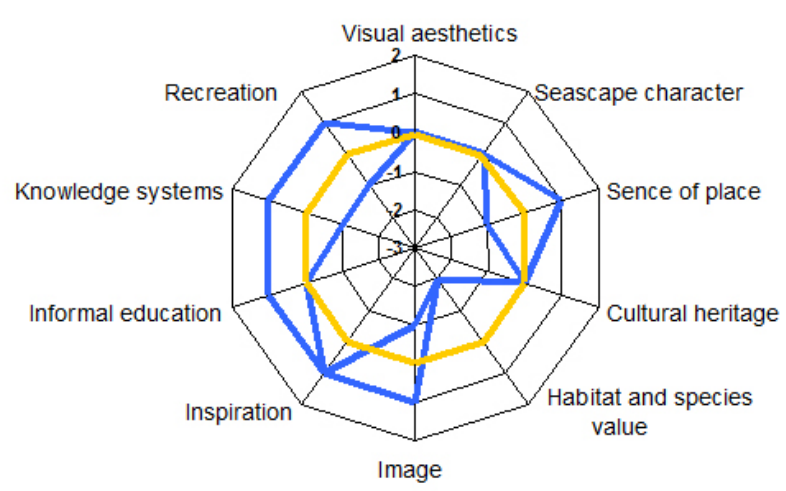

For many of the other cultural ecosystem service indicators shown, visibility is not the deciding factor because there are widespread general concerns about the suspected industrialization of the sea. As perceived by local residents, cultural ecosystem service losses would occur with respect to intrinsic sea values, i.e., loss of habitat and species values, but in many other categories, both losses and gains could result. OWF may bring new recreational opportunities, give the region a new sense of place as an energy region, or add to existing knowledge systems. Losses are mostly imagined if OWF pushes out existing values without offering a viable alternative. Acceptance of the value shift, as well as the willingness to actively promote or support it, thus ultimately depends on whether the gains, e.g., renewable energy or biodiversity, are considered more valuable than the losses, e. g., traditional seascape values or particular species.

Two possible trajectories thus present themselves for the seascape. Given the fact that no OWF is not an option, one possibility is the modification of the 'natural' seascape toward a semicultural seascape comprising both industrialized and natural elements. This requires limiting the areas for OWF as well as their careful siting, preserving some of the former attributes of the sea so that it can still be interpreted as a largely natural landscape. This option would potentially gain cultural ecosystem services, benefitting from both traditional and novel functions. The alternative is a loss of the natural seascape followed by a shift toward a purely industrial seascape. This option has lower integrity, validating fewer cultural ecosystem services. Of course, novel cultural ecosystem services could emerge in the industrial seascape, but it is uncertain whether 
Fig. 6. Offshore wind farming (OWF) in the German North Sea; potential socioeconomic system trajectories: A) development of a renewable energy region; and B) loss of traditional identity.

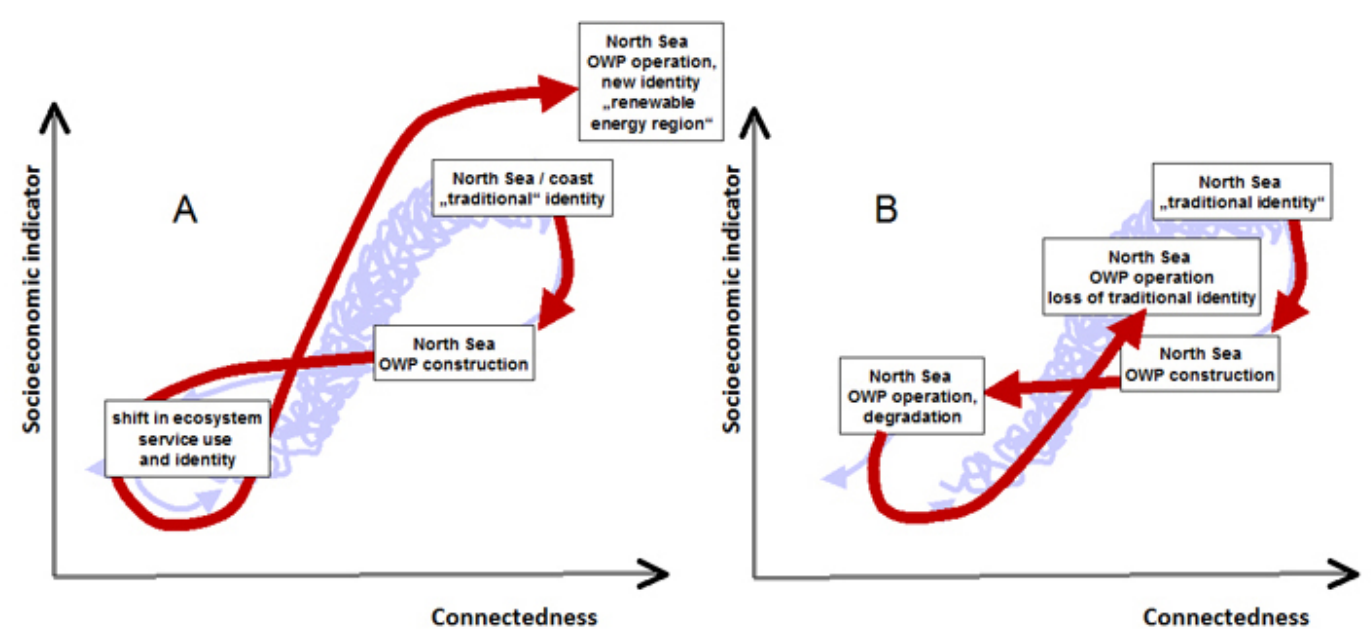

they would offset the losses in terms of 'natural' seascape benefits.

\section{Resilience of the socioeconomic system}

Unlike onshore wind, the driving forces behind OWF development in the German EEZ are largely external. Given the approvals already issued, OWF expansion in the German EEZ is a virtual certainty (BSH 2011), with the current planning framework leaving the region little option to block OWF (Bruns and Gee 2009). OWF is also much more difficult to realize than onshore wind because of the long planning horizons and high investment costs; an early citizen's offshore wind farm project in the region failed for these very reasons. However, the certainty of OWF also gives the region a reasonable planning horizon if it does choose to ride the boom. Although manufacture and construction are taking place elsewhere, it could invest in OWF management and servicing or other ancillary services.

The previous section has classified the socioeconomic system as a system in a late conservation phase, characterized by low flexibility and high vulnerability to external disturbances. The inflexibility of the system is enhanced by the restrictive institutional context, characterized by relatively inflexible, formal modes of governance (Bruns and Gee 2009, Kannen et al. 2010), and the region's inherent conservatism and reliance on existing values. Preserving traditional lifestyle, nature, and the existing quality of the landscape rank highly on the residents' agenda, which is incompatible with openness to large-scale innovation (Ratter et al. 2009, Gee 2010b). Although the region did have innovation potential with respect to onshore wind, this is not the case in the offshore sector, with no significant niches or sets of rules presently facilitating offshore wind industry development.
This leads to two conceivable system responses (Fig. 6). Given the fact that the region has no direct influence over developments in the sea, the choices are either to accept OWF and embrace it as an opportunity, or to resist it and seek to maintain the status quo. A regime shift toward a new system with greater connectedness is shown in A) on the left in Figure 6. This trajectory requires the validation of traditional ecosystem services, e.g., beauty of the seascape and high value of the marine environment, as well as new ecosystem services, e.g., wind energy, mariculture as co-use in OWF (MichlerCieluch and Krause 2008). Additionally, a structural shift would be required at the meso-scale, such as the development of new institutions, institutional responses to OWF, e.g., incentives or regional development programs, and new actor networks. Infrastructural investments would be needed to attract companies to the region. A key factor is the case study residents' willingness to embrace a new identity that includes OWF, which means a social shift in values and norms. The new value base could then be represented in a new regional identity, e.g., a renewable energy region, and accompanied by new forms of tourism marketing.

The more resilient or degrading socioeconomic system response is shown in B) on the right side (Fig. 6). Along this trajectory, connectedness would decrease after the OWF construction.

Given the prevailing conservative value system and restrictive institutional context, a transition based on socioeconomic system innovation seems a difficult prospect. Further difficulties arise from the fact that coastal regions in other federal states have already attracted the greater share of the OWF business. If OWF is rejected rather than harnessed, the socioeconomic system will likely remain more vulnerable to 
Table 2. Tipping points for regime shifts in the respective subsystems and the impact of the respective trajectories on selected ecosystem services.

\begin{tabular}{|c|c|c|c|c|c|c|c|}
\hline \multirow[t]{2}{*}{ Subsystem } & \multirow[t]{2}{*}{ Offshore wind farm scenario tipping points } & \multicolumn{6}{|c|}{ Impacts on ecosystem service provision } \\
\hline & & $\begin{array}{l}\text { Global } \\
\text { climate } \\
\text { regulation }\end{array}$ & $\begin{array}{l}\text { Provision } \\
\text { of food }\end{array}$ & $\begin{array}{l}\text { Provision } \\
\text { of wind } \\
\text { energy }\end{array}$ & $\begin{array}{l}\text { Aesthetics } \\
\text { of } \\
\text { seascape }^{\S}\end{array}$ & $\begin{array}{l}\text { Seascape } \\
\text { character, } \\
\text { sense of } \\
\text { place, } \\
\text { inspiration }^{\S}\end{array}$ & $\begin{array}{l}\text { Cultural } \\
\text { identity }\end{array}$ \\
\hline \multirow[t]{3}{*}{ Ecosystem } & Artificial reef emergence & + & + & + & & + & \\
\hline & Resilient ecosystem behavior & + & & + & & & + \\
\hline & Ecosystem degradation & + & - & + & - & - & - \\
\hline Seascape & OWF construction & + & $(+)$ & + & $+/-$ & $+/-$ & $+/-$ \\
\hline \multirow{2}{*}{$\begin{array}{l}\text { Socioeconomic } \\
\text { system }\end{array}$} & Energy region acceptance & + & & + & + & + & + \\
\hline & Loss of traditional identity and slow degradation & + & & + & - & - & - \\
\hline
\end{tabular}

gradual decline and be more susceptible to lock-in in a vulnerable regime.

\section{DISCUSSION}

The tipping points of the three subsystems under consideration and the impacts this would have on ecosystem services are shown in Table 2. Irrespective of any other trajectories, OWF will have positive impacts on global climate regulation through the provision of renewable energy. If artificial reefs develop for example, which seems a likely adaptive response over time, positive impacts will be noted for food provision at the ecosystem level. The consequences of the regime shift at the seascape level are open in that positive or negative impacts on cultural ecosystem services could ensue: the socioeconomic system benefits if it accepts a new image as an energy region; the reverse is true if it does not.

The interconnectedness of the adaptive cycles occurring at our case study scales is shown in Figure 7. The development of artificial reefs at the individual wind turbine pile scale (shown by indicators such as integrity, species composition) is the most localized and possibly slowest regime shift. The regime shift in the seascape would be the fastest shift in that impacts are immediate and not dependent on gradual change, although the shift would become more pronounced as more OWFs are built over time. The potential shift in the socioeconomic system is also likely to take some time for the necessary structural adjustments to be made and for new social values to become firmly anchored in the region. However, sudden change is possible even here, as evidenced by the change in societal energy values in response to events at Fukushima and the rapid response of German energy policy. General support for renewables is also present in the case study region (Gee $2010 a$ ). The overall social-ecological system in the case study region is thus shown to be influenced by a range of cumulative and sometimes cascading effects with different tipping points at different spatial scales.
Fig. 7. Panarchy of adaptive cycles acting at different spatial scales: A) individual turbine pile, B) offshore wind farm (OWF)/seascape, C) coastal region.

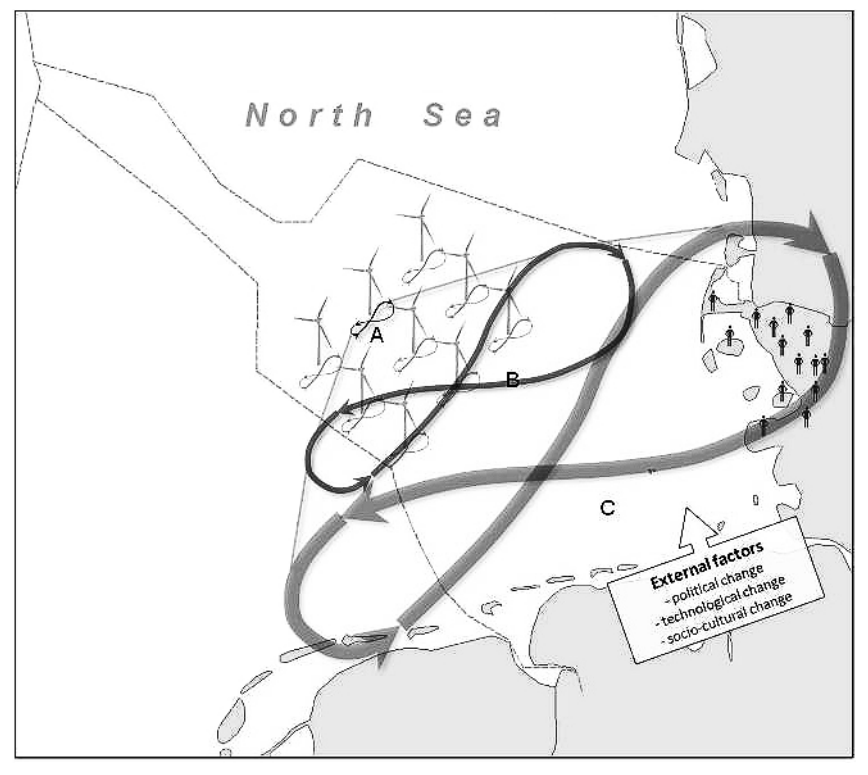

A synoptic overview of potential system trajectories and respective tipping points for the overall social-ecological system is provided in Figure 8. The cases described in our research are the two extreme trajectories; other trajectories are of course conceivable in-between.

\section{Trajectory I}

The ecological system reacts resiliently to the introduction of OWF (tipping point 1 in Fig. 8). No artificial reefs develop, so there is no added gain in ecosystem service supply besides wind energy. Moreover, no socioeconomic benefits are added 
to the region by OWF. Thus, no new identity emerges and regional policy makers continue to resist opportunities offered by OWF (tipping point 2). No new jobs or infrastructure are created. Although OWF does not cause an immediate collapse or broad-based regime shift of the overall system, the result is a gradual system decline because the opportunity to increase storage is lost and the social-ecological system remains vulnerable to alterations in external driving forces.

Fig. 8. Offshore wind power (OWP) development in the German North Sea; tipping points for potential system shifts: 1) ecosystem: artificial reef, resilient behavior or degradation; 2) socioeconomic system: acceptance or loss of identity.

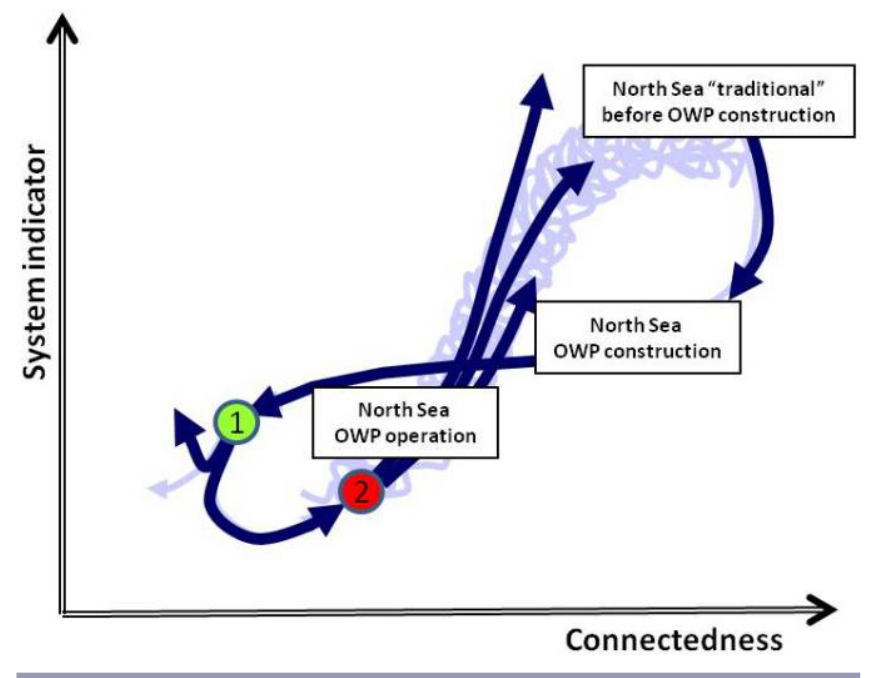

\section{Trajectory II}

The ecological system shows high adaptability to new OWF conditions and artificial reefs develop (tipping point 1). The supply of new ecosystem services emerges, some of which are compatible with existing ones. Several traditional cultural ecosystem services are lost, but these can be compensated for by the active exploitation of alternative services and the region's vision of a sustainable renewable energy region (tipping point 2). This new identity is encouraged and harnessed by policy makers, actively promoting the region as an investment region to companies. For human well-being, this new system may include greater job diversity, assuming OWF is not incompatible with tourism and fishery, the potential to halt negative demographic developments, and positive impacts on social and other infrastructure. Thus, the new system would be characterized by greater connectedness, expressed for example by linkages to the national and international electricity grid, internationally appreciated contributions to mitigate greenhouse gases, or accumulation of knowledge and capital.
These potential future system trajectories are summarized into the context of the original conceptual model developed for this case study (Fig. 9). An adaptive ecosystem response at the microscale would have secondary effects at the meso-scale, where artificial reef ecosystems would contribute to a larger scale ecological regime shift with increased ecosystem functions, e.g., higher ecosystem storage capacity, increasing biodiversity, and availability of fish (Punt et al. 2009). This would increase the supply of selected ecosystem services, e. g., the provisioning ecosystem service fish, which could stabilize the fishing sector. On the other hand, large-scale OWF would cause habitat loss and the loss of feeding and migration routes, impacting on ecosystem functions and cultural ecosystem services. At the same time, OWF triggers an adaptive response in the seascape in that it shifts toward a more industrial seascape, with impacts felt at the level of cultural ecosystem services. If the region chooses to embrace these new cultural ecosystem services and a new identity as an energy region, OWF could trigger a positive transition of the socioeconomic system and facilitate a new forward loop of development leading to the accumulation of new social and economic capital. At this point, the important role of external factors in facilitating a positive transition needs to be emphasized, such as the continued national support of OWF and continuation of the existing renewable energy policy.

Fig. 9. Dynamic conceptual model illustrating the linkages between the offshore wind farm (OWF) case study and the potential future system trajectories.

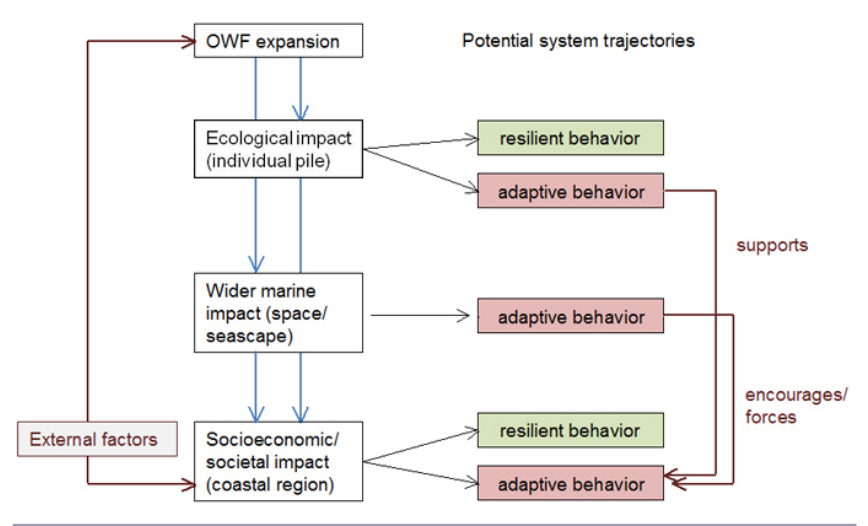

How likely is it that the region will be able to utilize OWF to its benefit? The factors that need to converge to facilitate a socioeconomic transition can be highlighted by comparing the national German situation to that in the case study region. Nationally, OWF can safely be described as a system innovation that is realized by a variety of participants within the system and that fundamentally changes both the structure of the system and the relationship among participants (Loorbach and Rotmans 2006). As such, the system is currently engaged in a transition involving convergences and 
trends at the micro-, meso- and macroscale. OWF in Germany is driven by national and international renewable energy policy and societal preference for renewables, indicating a changing value base as an important enabling factor. At the meso-scale, new companies are emerging across Germany, new actor networks and alliances to push OWF, and licensing procedures, sparking the development of new institutional frameworks such as maritime spatial planning. At the microscale are individual preferences and actions, including support and investment in renewables.

Similar trends can be noted in the case study region. Here however, the lack of convergence leads to a different outcome. The local resident survey indicated general support for renewable energies, confirming the national trend with respect to wider societal values. As an early adopter and innovator, the region was certainly in the predevelopment and take-off phases of transition with respect to onshore wind, with many small businesses starting there, new discourses taking place in the region (Fuchs 2006), and the emergence of new actor networks and companies. However, although the wind industry has led to the development of new links and nodes in the system, these have remained fragile. Onshore wind industry companies have since moved out of the region, leading to the loss of nodes that were not replaced. Largely because of the lack of timely political will and business acumen, e.g., failure to offer incentives or to make use of investment opportunities, the potential to use OWF as an additional driver and initiate a take-off and stabilization phase has so far passed the case study region by.

\section{CONCLUSION}

As shown in our paper, OWF-induced changes and cascading effects in the coastal-marine social-ecological system can be captured by linking the concepts of resilience, regime shifts, and ecosystem services (research question 3). Using the OWF development scenarios and the modeling and survey results obtained in the Coastal Futures project, potential regime shifts were identified at three spatial scales (research question 1). These regime shifts were then shown to have impacts on other system domains, with shifts in ecosystem service supply used as the link between the regime shifts in the sea and the response of the socioeconomic system on the coast (research question 2). The potential response of the socioeconomic system was shown to be dependent on the ability of the socioeconomic system to overcome endogenous as well as exogenous constraints. Willingness to embrace OWF as a contributor to a new regional identity emerged as a key factor determining the trajectory of the system. This new identity accepts that former seascape-based values will be lost and makes active use of the opportunity OWF presents to reduce its structural weakness and dependence on tourism as the key economic sector. Lock-in and a gradual negative transition are thus avoided.
The respective trajectories and the correlations shown in this paper should be seen as metaphors of extreme developments rather than exact forecasts of what will happen in future (Burkhard et al. 2011b). We emphasize that our assumptions on future dynamics are hypotheses based on many interdependent assumptions (Carpenter and Gunderson 2001). For example, the ecological integrity assessments rely mainly on modeling of dynamic system behavior (Bass 1998). The socioeconomic assessments are based on survey results obtained in the region at a certain point in time. Validation of these results over the longer term would be needed for more robust conclusions to be drawn.

We consciously avoid any rating of the system shifts described and do not make any value judgments as to whether resilient or adaptive responses would be preferable. At all three system scales, both trajectories were shown to have advantages and disadvantages, with system degradation clearly the most obvious disadvantage. For the region, both the 'traditional' and 'progressive' trajectory could mean sustainability, although the 'traditional' trajectory would leave the region more structurally vulnerable and susceptible to changes in external drivers. The advantage of the "progressive" trajectory mainly lies in the ability to form new socioeconomic nodes and links, thus increasing connectedness and therefore the ability of the system to cope with disturbance.

Dynamics in social-ecological systems are very complex, topic-related (socioeconomic versus ecological system components), observer-influenced, and spatially as well as temporally scale-dependent (Holling 2001, Allen and Holling 2008). Therefore, any averaging of particular system components or the transfer of particular results to other systems is difficult. Nevertheless, we believe that the conceptual framework presented here is transferable to other case study examples, offering added value not only to the existing Coastal Futures results, but also extending the application of the individual concepts used. Practical applications include the identification of critical intervention points for social-ecological system management, both in the ecological and the socioeconomic spheres. A logical next step would be to consider how the social-ecological system could be managed to maximize gains at all scales.

The results and related hypotheses also point the way for further trans- and interdisciplinary integration, not least in the development of ecological and socioeconomic indicators that would allow the monitoring of value and state shifts. These indicators are needed to assess trade-offs between different forms of human activities and their effects on the supply of ecosystem services. Ultimately though, management for multiple ecosystem services has to take into account the various impacts of human action and will therefore always be some kind of compromise between different socioeconomic interests and environmental necessities. 
Responses to this article can be read online at: http://www.ecologyandsociety.org/issues/responses. $\mathrm{php} / 5207$

\section{Acknowledgments:}

The project Zukunft Küste - Coastal Futures was funded by the German Ministry of Education and Research (BMBF FKZ $03 F 0476 B$ ). We would like to thank the anonymous reviewers for their constructive comments on the first draft of our paper.

\section{LITERATURE CITED}

Allen, C., and C. S. Holling. 2008. Discontinuities in ecosystems and other complex systems. Columbia University Press, New York, New York, USA.

Bass, B. 1998. Applying thermodynamic orientors: goal functions in the Holling figure-eight model. Pages 193-208 in F. Müller and M. Leupelt, editors. Eco targets, goal functions, and orientors. Springer-Verlag, Berlin Heidelberg, Germany. http://dx.doi.org/10.1007/978-3-642-58769-6_12

Bossel, H. 2000. Sustainability: application of systems theoretical aspects to societal development. Pages 519-536 in S. E. Jørgensen and F. Müller, editors. Handbook of ecosystem theories and management. Lewis, Boca Raton, Florida, USA.

Bruns, A., and K. Gee. 2009. From state-centered decisionmaking to participatory governance - planning for offshore wind farms and the implementation process of the Water Framework Directive in northern Germany. GAIA 18 (2):150-157.

Bruns, A., and K. Gee. 2010. Der Küsten - und Meeresraum zwischen traditionellen Küstenbildern und neuen Steuerungsformen für eine nachhaltige Entwicklung. Berichte zur deutschen Landeskunde. Deutsche Akademie für Landeskunde, Leipzig, Germany.

Bundesamt für Bauwesen und Raumordnung (BBR). 2005. Raumordnungsbericht 2005. BBR, Government of Germany, Bonn, Germany.

Bundesamt für Seeschifffahrt und Hydrographie (BSH). 2011. Windfarms. BSH, Hamburg, Germany. [online] URL: http:// www.bsh.de/en/Marine uses/Industry/Wind farms/index.jsp

Burkhard, B., B. D. Fath, and F. Müller. 2011b. Adapting the adaptive cycle: hypotheses on the development of ecosystem properties and services. Ecological Modelling 222(16):28782890. http://dx.doi.org/10.1016/j.ecolmodel.2011.05.016
Burkhard, B., S. Opitz, H.-J. Lenhart, K. Ahrendt, S. Garthe, B. Mendel, and W. Windhorst. 2011a. Ecosystem based modeling and indication of ecological integrity in the German North Sea - case study offshore wind parks. Ecological Indicators 11:168-174. http://dx.doi.org/10.1016/j. ecolind.2009.07.004

Bürkner, H.-J. 2010. Vulnerabilität und Resilienz Forschungsstand und sozialwissenschaftliche Untersuchungsperspektiven. Working Paper, Leibnitz-Institut für Regionalentwicklung und Strukturplanung, Erkner, Germany. [online] URL: http://www.irs-net.de/download/wp vr.pdf

Busch, M., B. Burkhard, M. Lange, K. Gee, and N. Stelljes. 2010. Impacts of offshore wind farms on the provision of ecosystem services and human well-being. Pages 121-160 in M. Lange, B. Burkhard, S. Garthe, K. Gee, A. Kannen, H. Lenhart, and W. Windhorst, editors. Analyzing coastal and marine changes: offshore wind farming as a case study. LOICZ Research \& Studies No. 36. GKSS Research Centre, Geesthacht, Germany.

Busch, M., K. Gee, B. Burkhard, M. Lange, and N. Stelljes. 2011. Conceptualizing the link between marine ecosystem services and human well-being: the case of offshore wind farming. International Journal of Biodiversity Science, Ecosystem Services \& Management 7(3):190-203. http://dx. doi.org/10.1080/21513732.2011.618465

Carpenter, S. R., and L. H. Gunderson. 2001. Coping with collapse: ecological and social dynamics in ecosystem management. Bioscience 51(6):451-457. http://dx.doi. org/10.1641/0006-3568(2001)051[0451:CWCEAS]2.0.CO;2

Department of Trade and Industry (DTI). 2005. Guidance on the assessment of the impact of offshore wind farms: seascape and visual impact report. DTI, UK Government, London, UK.

Exo, K.-M., O. Hüppop, and S. Garthe. 2003. Birds and offshore wind farms: a hot topic in marine ecology. Wader Study Group Bulletin 100:50-53.

Folke, C., S. Carpenter, T. Elmqvist, L. Gunderson, C. S. Holling, and B. Walker. 2002a. Resilience and sustainable development: building adaptive capacity in a world of transformations. Ambio 31:437-440.

Folke, C., J. Colding, and F. Berkes. 2002b. Synthesis: building resilience and adaptive capacity in social-ecological systems. Pages 352-387 in F. Berkes, J. Colding, and C. Folke, editors. Navigating social-ecological systems: building resilience of complexity and change. Cambridge University Press, Cambridge, UK. http://dx.doi.org/10.1017/ CBO9780511541957.020

Fuchs, S. 2006. Medienanalyse - Das Thema Offshore Windkraft in der lokalen Presse an der Westküste Schleswig- 
Holsteins. Arbeitspapier Vers II. Coastal Futures, Geesthacht, Germany.

Gee, K. 2010a. Offshore wind power development as affected by seascape values on the German North Sea coast. Land Use Policy 27:185-194. http://dx.doi.org/10.1016/j.landusepol.2009.05.003

Gee, K. 2010b. Sea use and offshore wind farming. Pages 22-29 in M. Lange, B. Burkhard, S. Garthe, K. Gee, A. Kannen, H. Lenhart, and W. Windhorst, editors. Analyzing coastal and marine changes: offshore wind farming as a case study. LOICZ Research \& Studies No. 36. GKSS Research Centre, Geesthacht, Germany.

Gee, K., and B. Burkhard. 2010. Cultural ecosystem services in the context of offshore wind farming: a case study from the west coast of Schleswig-Holstein. Ecological Complexity 7 (3):349-358. http://dx.doi.org/10.1016/j.ecocom.2010.02.008

Geels, F. W., and J. Schot. 2007. Typology of sociotechnical transition pathways. Research Policy 36:399-417. http://dx. doi.org/10.1016/j.respol.2007.01.003

Gill, A. B. 2005. Offshore renewable energy: ecological implications of generating electricity in the coastal zone. Journal of Applied Ecology 42(4):605-615. http://dx.doi. org/10.1111/j.1365-2664.2005.01060.x

Gunderson, L. H., and C. S. Holling. 2002. Panarchy: understanding transformations in human and natural systems. Island Press, Washington, D.C., USA.

Hasse, J. 2007. "Nordseeküste" - Die touristische Konstruktion besserer Welten. Zur Codierung einer Landschaft. Pages 239-258 in N. Fischer, S. MüllerWusterwitz, and B. Schmidt-Lauber, editors. Inszenierungen der Küste. Reimer-Verlag, Berlin, Germany.

Hill, M., J. Briggs, P. Minto, D. Bagnall, K. Foley, and A. Williams. 2001. Guide to best practice in seascape assessment. Maritime Ireland/Wales INTERREG 1994-1999. Countryside Council for Wales, Brady Shipman Martin, and University College Dublin, Dublin, Ireland.

Holling, C. S. 2001. Understanding the complexity of economic, ecological, and social systems. Ecosystems 4 (5):390-405. http://dx.doi.org/10.1007/s10021-001-0101-5

Inger, R., M. J. Attrill, S. Bearhop, A. C. Broderick, W. J. Grecian, D. J. Hodgson, C. Mills, E. Sheehan, S. C. Votier, M. J. Witt, and B. J. Godley. 2009. Marine renewable energy: potential benefits to biodiversity? An urgent call for research. Journal of Applied Ecology 46(6):1145-1153. http://dx.doi. org/10.1111/j.1365-2664.2009.01697.x

Janssen, M. A., Ö. Bodin, J. M. Anderies, T. Elmqvist, H. Ernstson, R. R. J. McAllister, P. Olsson, and P. Ryan. 2006. Toward a network perspective of the study of resilience in social-ecological systems. Ecology and Society 11(1): 15. [online] URL: www.ecologyandsociety.org/vol11/iss1/art15

Jørgensen, S. E., B. D. Fath, S. Bastianoni, J. C. Marques, F. Müller, S. N. Nielsen, B. C. Patten, E. Tiezzi, and R. E. Ulanowicz. 2007. A new ecology - systems perspective. Elsevier, Amsterdam, The Netherlands.

Kannen, A., and B. Burkhard. 2009. Integrated assessment of coastal and marine changes using the example of offshore wind farms: the Coastal Futures approach. GAIA 18(3):229-238.

Kannen, A., K. Gee, and A. Bruns. 2010. Governance aspects of offshore wind energy and maritime development. Pages 170-190 in M. Lange, B. Burkhard, S. Garthe, K. Gee, A. Kannen, H. Lenhart, and W. Windhorst, editors. Analyzing coastal and marine changes: offshore wind farming as a case study. LOICZ Research \& Studies No. 36. GKSS Research Centre, Geesthacht, Germany.

Kinzig, A. P., P. Ryan, M. Etienne, H. Allison, T. Elmqvist, and B. H. Walker. 2006. Resilience and regime shifts: assessing cascading effects. Ecology and Society 11(1): 20. [online] URL: http://www.ecologyandsociety.org/vol11/iss1/ $\underline{\operatorname{art} 20 /}$

Kirchhoff, T., F. S. Brand, D. Hoheise, and V. Grimm. 2010. The one-sidedness and cultural bias of the resilience approach. GAIA 19(1):25-32.

Kraberg, A. C., N. Wasmund, J. Vanaverbeke, D. Schiedek, K. H. Wiltshire, and N. Mieszkowska. 2011. Regime shifts in the marine environment: the scientific basis and political context. Marine Pollution Bulletin 62:7-20. http://dx.doi. org/10.1016/j.marpolbul.2010.09.010

Kreis Dithmarschen. 2009. Teilfortschreibung Windenergie 2009 - Begrenztes Kontingent optimal nutzen. Kreis Dithmarschen, Heide, Germany. [online] URL: http://www. dithmarschen.de/index.phtml?call=detail\&css= $\& \mathrm{La}=1 \& \mathrm{FID}=647.2965 .1 \& \mathrm{sNavID}=1599.21 \& \mathrm{~m} \%$ 20NavID $=164.674 \& \mathrm{ffmod}=$ pres $\& \mathrm{ffsm}=1$

Kumar, P., editor. 2010. The economics of ecosystems and biodiversity - ecological and economic foundations. Earthscan. London, UK.

Lange, M., B. Burkhard, S. Garthe, K. Gee, A. Kannen, H. Lenhart, and W. Windhorst. 2010. Analyzing coastal and marine changes: offshore wind farming as a case study. LOICZ Research \& Studies No. 36. GKSS Research Centre, Geesthacht, Germany.

Lenhart, H., K. Ahrendt, B. Burkhard, S. Garthe, D. Gloe, W. Kühn, B. Mendel, P. Nerge, S. Opitz, and A. Schmidt. 2010. Ecological impact assessment. Pages 52-96 in M. Lange, B. Burkhard, S. Garthe, K. Gee, A. Kannen, H. Lenhart, and W. Windhorst, editors. Analyzing coastal and marine changes: offshore wind farming as a case study. LOICZ Research \& 
Studies No. 36. GKSS Research Centre, Geesthacht, Germany.

Licht-Eggert, K., C. Froh, I. Büsch, and A. Bruns. 2007. Lebensqualität und soziale Infrastrukturen an der schleswigholsteinischen Westküste: Bericht zum Social State in den Szenarien von Coastal Futures. Arbeitspapier Vers IV. Coastal Futures, Geesthacht, Germany.

Loorbach, D., and J. Rotmans. 2006. Managing transitions for sustainable development. Pages 187-206 in X. Olsthoorn and A. J. Wieczorek, editors. Understanding industrial transformation: views from different disciplines. Environment and Policy series, Springer, Berlin, Heidelberg, Germany. http://dx.doi.org/10.1007/1-4020-4418-6 10

Michler-Cieluch, T., and G. Krause. 2008. Perceived concerns and possible management strategies for governing 'wind farm-mariculture next term integration'. Marine Policy 32 (6):1013-1022. http://dx.doi.org/10.1016/j.marpol.2008.02.008

Millennium Ecosystem Assessment (MA). 2005. Ecosystems and human well-being: synthesis report. Island Press, Washington, D.C., USA.

Müller, F., B. Burkhard, and F. Kroll. 2010. Resilience, integrity and ecosystem dynamics: bridging ecosystem theory and management. Pages 221-242 in J. C. Otto and R. Dikau, editors. Landform - structure, evolution, process control. Lecture Notes in Earth Sciences Series. Vol. 115. Springer, Berlin, Heidelberg, Germany. http://dx.doi.org/10.1007/978-3-540-75761-0 14

Nilsson, L., and M. Green. 2011. Birds in southern Öresund in relation to the wind farm at Lillgrund. Final report of the monitoring program 2001-2011. Commissioned by Vattenfall Vindkraft AB, Lund, Sweden.

Petersen, J. K., and T. Malm. 2006. Offshore windmill farms: threats to or possibilities for the marine environment. Ambio 35(2):75-80. http://dx.doi.org/10.1579/0044-7447(2006)35 [75:OWFTTO]2.0.CO;2

Prognos, AG. 2005. Prognos Zukunftsatlas 2010 Deutschlands Regionen im Zukunftswettbewerb. Prognos, Berlin, Bremen, Dusseldorf, Germany. [online] URL: http:// www.prognos.com/zukunftsatlas

Punt, M. J., R. A. Groeneveld, E. C. van Ierland, and J. H. Stel. 2009. Spatial planning of offshore wind farms: a windfall to marine environmental protection? Ecological Economics 69:93-103. http://dx.doi.org/10.1016/j.ecolecon.2009.07.013

Ratter, B. M. W., and K. Gee. 2012. Heimat - a German concept of regional perception and identity as a basis for coastal management in the Wadden Sea. Ocean \& Coastal Management 68:127-137. http://dx.doi.org/10.1016/j. ocecoaman.2012.04.013
Ratter, B. M. W., M. Lange, and C. Sobiech. 2009. Heimat, Umwelt und Risiko an der deutschen Nordseeküste. Die Küstenregion aus Sicht der Bevölkerung. GKSS 2009/10, GKSS Forschungszentrum, Geesthacht, Germany.

Scheffer, M., and S. R. Carpenter. 2003. Catastrophic regime shifts in ecosystems: linking theory to observation. Trends in Ecology \& Evolution 18(12):648-656. http://dx.doi. org/10.1016/j.tree.2003.09.002

Skeate, E. R., M. R. Perrow, and J. J. Gilroy. 2012. Likely effects of construction of Scroby Sands offshore wind farm on a mixed population of harbour Phoca vitulina and grey Halichoerus grypus seals. Marine Pollution Bulletin 64:872-881. http://dx.doi.org/10.1016/j.marpolbul.2012.01.029

Statistisches Amt für Hamburg und Schleswig-Holstein. 2007. Statistisches Jahrbuch Schleswig-Holstein 2006. Statistisches Amt für Hamburg und Schleswig-Holstein, Hamburg, Germany. [online] URL: http://www.statistik-nord.de/ uploads/tx_standocuments/JB2006_SH.pdf

Vattenfall AB. 2006. Horns Rev Offshore Wind Farm: annual status report for the environmental monitoring programme 2005. Report No. 6659. Vattenfall, Fredericia, Denmark. [online] URL: http://www.ens.dk/da-DK/UndergrundOgForsyning/ VedvarendeEnergi/Vindkraft/Havvindmoeller/Miljoepaavirkninger/ Miljoeunders\%C3\%B8gelser\%20for\%20specifikke\%20projekter/ Documents/Horns\%20Rev\%20I/status\%202005.pdf

Vattenfall AB. 2009. Lillgrund Offshore Wind Farm. Environmental monitoring of marine flora \& fauna. Report 019-10. Vattenfall, Landskrona, Sweden. [online] URL: http://www.vattenfall.se/sv/file/Environmental_Monitoring_Flora Fauna 17379857.pdf

Walker, B. H., J. M. Anderies, A. P. Kinzig, and P. Ryan. 2007. Exploring resilience in social-ecological systems. CSIRO, Collingwood, Victoria, Australia.

Walker, B. H., L. H. Gunderson, A. P. Kinzig, C. Folke, S. R. Carpenter, and L. Schulz. 2006. A handful of heuristics and some propositions for understanding resilience in socialecological systems. Ecology and Society 11(1): 13. [online] URL: http://www.ecologyandsociety.org/vol11/iss1/art13/

Walker, B. H., and D. Salt. 2006. Resilience thinking. Sustaining ecosystems and people in a changing world. Island Press, Washington, D.C., USA.

Wilhelmsson, D., and T. Malm. 2008. Fouling assemblages on offshore wind power plants and adjacent substrata. Estuarine, Coastal and Shelf Science 79:459-466. http://dx. doi.org/10.1016/j.ecss.2008.04.020

Wilhelmsson, D., T. Malm, and M. C. Öhman. 2006. The influence of offshore windpower on demersal fish. ICES Journal of Marine Science 63:775-784. http://dx.doi. org/10.1016/j.icesjms.2006.02.001 
Wizelius, T. 2007. Developing wind power projects: theory and practice. Earthscan, London, UK.

Wolsink, M. 2010. Near-shore wind power-protected seascapes, environmentalists' attitudes, and the technocratic planning perspective. Land Use Policy 27:195-203. http://dx. doi.org/10.1016/j.landusepol.2009.04.004

Ziesemer, K., and B. Zahl. 2005. Akteursnetzwerke an der Westküste Schleswig-Holsteins - Darstellung ausgewählter sozioökonomischer Voraussetzungen der Region. Working Paper No. 2. Coastal Futures, Geesthacht, Germany. 